\title{
Structural and Dynamical Impact of Water Molecules at Substrate- or Product-Binding Sites in \\ Human GMPR Enzyme: A Study by Molecular Dynamics Simulations
}

\author{
Hridoy R. Bairagya*1\#, Alvea Tasneem², \\ Gyan Prakash Rai ${ }^{2}$, Saima Reyaz \\ ${ }^{1}$ Department of Chemistry, University of Cambridge, Lensfield Road, CB2 1EW, \\ Cambridge, UK \\ ${ }^{2}$ Department of Computer Science, Jamia Millia Islamia, Jamia Nagar, \\ Okhla, New Delhi-110025, India
}

Email: hbairagya@gmail.com, hridoy_bolpur@ rediffmail.com

* Corresponding Author:

Dr. Hridoy Ranjan Bairagya.

Tel: $+91-8277145815$

Email: hbairagya@gmail.com 


\section{SUPPLEMENTARY TABLES}

Table S1: List of X-ray crystal structures of human GMP reductase enzyme used in the computational study.

\begin{tabular}{|c|c|c|c|c|c|c|c|c|}
\hline \multirow{2}{*}{ 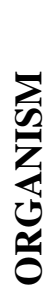 } & \multirow[t]{2}{*}{$\begin{array}{c}\text { PDB } \\
\text { ID }\end{array}$} & \multirow[t]{2}{*}{$\begin{array}{l}\text { RESOLUTION } \\
(\AA)\end{array}$} & \multirow{2}{*}{$\begin{array}{c}\text { R- } \\
\text { VALUE } \\
\text { FREE/ } \\
\text { R- } \\
\text { VALUE } \\
\text { WORK }\end{array}$} & \multirow[t]{2}{*}{$\begin{array}{l}\text { SPACE } \\
\text { GROUP }\end{array}$} & \multirow{2}{*}{$\begin{array}{l}\text { NUMBER OF } \\
\text { WATER } \\
\text { MOLECULES/ } \\
\text { LIGANDS }\end{array}$} & \multicolumn{2}{|c|}{ UNIT CELL } & \multirow[t]{2}{*}{$\mathbf{p H}$} \\
\hline & & & & & & $\begin{array}{c}\text { Length } \\
(\AA)\end{array}$ & Angle (o) & \\
\hline 实 & 2BLE & 1.90 & $0.22 / 0.11$ & P $422_{1} 2$ & $\begin{array}{c}126 / \\
\text { Substrate } \\
\text { (5GP/GMP) }\end{array}$ & $\begin{array}{c}a=117.78, \\
b=117.78, \\
c=54.42\end{array}$ & $\begin{array}{l}\alpha=90.0 \\
\beta=90.0 \\
\gamma=90.0\end{array}$ & 6.5 \\
\hline 总 & 2BWG & 2.40 & $0.24 / 0.19$ & $\mathrm{P} 12{ }_{1} 1$ & $\begin{array}{c}60 / \\
\text { Substrate } \\
\text { (5GP/GMP) }\end{array}$ & $\begin{array}{c}a=55.31, \\
b=114.41, \\
c=115.12\end{array}$ & $\begin{array}{c}\alpha=90.0 \\
\beta=102.7 \\
\gamma=90.0\end{array}$ & NA \\
\hline \multirow{3}{*}{$\sum_{0}^{=1}$} & $2 \mathrm{~A} 7 \mathrm{R}$ & 3.00 & $0.27 / 0.15$ & $\mathrm{P} 3221$ & $\begin{array}{c}3 / \\
\text { Substrate } \\
(5 \mathrm{GP} / \mathrm{GMP})\end{array}$ & $\begin{array}{l}a=110.56, \\
b=110.56, \\
c=209.75\end{array}$ & $\begin{array}{l}\alpha=90.0 \\
\beta=90.0 \\
\gamma=120.0\end{array}$ & 5.6 \\
\hline & $2 \mathrm{BZN}$ & 2.15 & $0.21 / 0.15$ & $\mathrm{P} 2{ }_{1} 2_{1} 2_{1}$ & $\begin{array}{c}219 / \\
\text { Product(IMP) }\end{array}$ & $\begin{array}{l}a=131.29, \\
b=141.35, \\
c=164.89\end{array}$ & $\begin{array}{l}\alpha=90.0 \\
\beta=90.0 \\
\gamma=90.0\end{array}$ & 5.8 \\
\hline & 2C6Q & 1.70 & $0.20 / 0.16$ & P $22_{1} 2_{1}$ & $\begin{array}{c}302 / \\
\text { Product + Cofactor } \\
\text { (IMP+NDP/NADPH) }\end{array}$ & $\begin{array}{l}a=131.67, \\
b=141.36, \\
c=164.31\end{array}$ & $\begin{array}{l}\alpha=90.0 \\
\beta=90.0 \\
\gamma=90.0\end{array}$ & NA \\
\hline
\end{tabular}

NA: Not available. 5GP/GMP: guanosine-5'-monophosphate, IMP: inosine-5'monophosphate, NDP: NADPH (nicotinamide adenine dinucleotide phosphate) 
Table S2: Comparative analysis between X-ray structures of hGMPR-I and II on the vicinity of interactions at substrate- or product-binding pocket. The distances $(\AA)$ are measured from the $\mathrm{C} 2$ atom of the substrate (GMP/5GP) or product (IMP) to catalytic and noncatalytic residues.

\begin{tabular}{|c|c|c|c|c|c|}
\hline \multirow{3}{*}{ 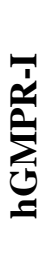 } & X-Ray Structure & $\begin{array}{l}\text { Cys186 } \\
\text { (SG) }\end{array}$ & $\begin{array}{l}\text { Thr188 } \\
\text { (OG1) }\end{array}$ & $\begin{array}{c}\text { Glu289 } \\
\text { (OE) }\end{array}$ & $\begin{array}{c}\text { Asp219 } \\
\text { (OD) }\end{array}$ \\
\hline & 2BLE & 4.15 & 7.13 & 10.37 & 8.24 \\
\hline & $\begin{array}{c}\text { (C2 of } 5 \mathrm{GP} / \mathrm{GMP}) \\
2 \mathrm{BWG} \\
(\mathrm{C} 2 \text { of } 5 \mathrm{GP} / \mathrm{GMP})\end{array}$ & 4.01 & 6.83 & 10.22 & 7.82 \\
\hline \multirow{3}{*}{ 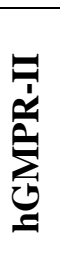 } & $\begin{array}{c}2 \mathrm{~A} 7 \mathrm{R} \\
\text { (C2 of } 5 \mathrm{GP} / \mathrm{GMP})\end{array}$ & 3.92 & 4.49 & 10.40 & 8.18 \\
\hline & $\begin{array}{c}2 \mathrm{BZN} \\
\text { (C2 of IMP) }\end{array}$ & 2.59 & 4.15 & 5.76 & 8.50 \\
\hline & $\begin{array}{c}2 \mathrm{C} 6 \mathrm{Q} \\
\text { (C2 of IMP) } \\
\end{array}$ & 2.31 & 3.88 & 5.97 & 8.48 \\
\hline
\end{tabular}

Table S3: Comparative analysis of substrate-/product-binding pocket between MD structures (different ligand-bound conformations) of hGMPR-I and II. The differences in distances ( $⿱$ ) of the two atoms from C2 of 5GP or IMP to catalytic or noncatalytic residues during MD simulation are measured.

\begin{tabular}{|c|c|c|c|c|c|c|c|c|c|}
\hline \multirow{2}{*}{$\begin{array}{c}\text { Ligand } \\
\text { bound MD } \\
\text { structures }\end{array}$} & \multirow{2}{*}{$\stackrel{\text { Residues }}{\longrightarrow}$} & \multicolumn{2}{|c|}{$\begin{array}{l}\text { C186 } \\
\text { (SG) }\end{array}$} & \multicolumn{2}{|c|}{$\begin{array}{l}\text { T188 } \\
\text { (OG1) }\end{array}$} & \multicolumn{2}{|c|}{$\begin{array}{l}\text { E289 } \\
\text { (OE) }\end{array}$} & \multicolumn{2}{|c|}{$\begin{array}{l}\text { D219 } \\
\text { (OD) }\end{array}$} \\
\hline & & I & II & I & II & I & II & I & II \\
\hline GMP & $\begin{array}{c}\mathrm{C} 2 \text { of } \\
5 \mathrm{GP} / \mathrm{GMP}\end{array}$ & 0.33 & 0.91 & 0.15 & 0.33 & 0.62 & 1.20 & 0.67 & 0.98 \\
\hline $\begin{array}{c}\text { GMP- } \\
\text { NADPH } \\
\end{array}$ & $\begin{array}{c}\mathrm{C} 2 \text { of } \\
5 \mathrm{GP} / \mathrm{GMP}\end{array}$ & 0.84 & 1.00 & 0.44 & 3.91 & 0.88 & 2.01 & 0.53 & 0.18 \\
\hline $\begin{array}{c}\text { IMP- } \\
\text { NADPH }\end{array}$ & C2 of IMP & 0.24 & 0.98 & 0.96 & 0.18 & 0.19 & 0.62 & 1.30 & 0.88 \\
\hline IMP & C2 of IMP & 0.77 & 0.30 & 0.49 & 2.84 & 0.23 & 0.77 & 1.25 & 0.41 \\
\hline
\end{tabular}

Abbreviation: GMP or 5GP: guanosine-5'-monophosphate, IMP: inosine-5'-monophosphate, NDP or NADPH: nicotinamide adenine dinucleotide phosphate; I: Isoform-I (2BLE); II: Isoform-II (2C6Q) of hGMPR. 
Table S4: Comparative study of conserved water molecules between MD and X-ray structures of hGMPR enzyme.

\begin{tabular}{c|cc|cc}
\hline $\begin{array}{c}\text { Water } \\
\text { Sites }\end{array}$ & \multicolumn{2}{|c|}{$\begin{array}{c}\text { Structure of } \\
\text { hGMPR-I } \\
\text { (PDB Id: 2BLE) }\end{array}$} & \multicolumn{2}{c}{$\begin{array}{c}\text { Structure of } \\
\text { hGMPR-II } \\
\text { (PDB Id: } \mathbf{2 C 6})\end{array}$} \\
\cline { 2 - 5 } Crystal & MD & Crystal & MD \\
\hline W1 & - & W1 & - & - \\
W2 & - & - & - & W2 \\
W3 & - & - & W2297 & W3 \\
W4 & - & W4 & - & - \\
W5 & - & W5 & - & - \\
W6 & - & W6 & - & - \\
W7 & - & - & - & W7 \\
W8 & - & - & - & W8 \\
W9 & - & W9 & - & W9 \\
W10 & - & - & - & W10 \\
W11 & W2077 & W11 & W2050 & W11 \\
W12 & - & W12 & - & W12 \\
W13 & - & W13 & - & - \\
W14 & W2125 & W14 & - & W14 \\
W15 & W2100 & W15 & W2209 & - \\
W16 & W2126 & W16 & W2294 & W16 \\
W17 & - & - & - & W17 \\
W18 & - & - & - & W18 \\
W19 & W2082 & W19 & W2295 & W19 \\
\hline
\end{tabular}

*Bold marked water molecules represent that they are conserved in both MD and X-ray structures ** ' -6 indicates not the availability of water molecules. 


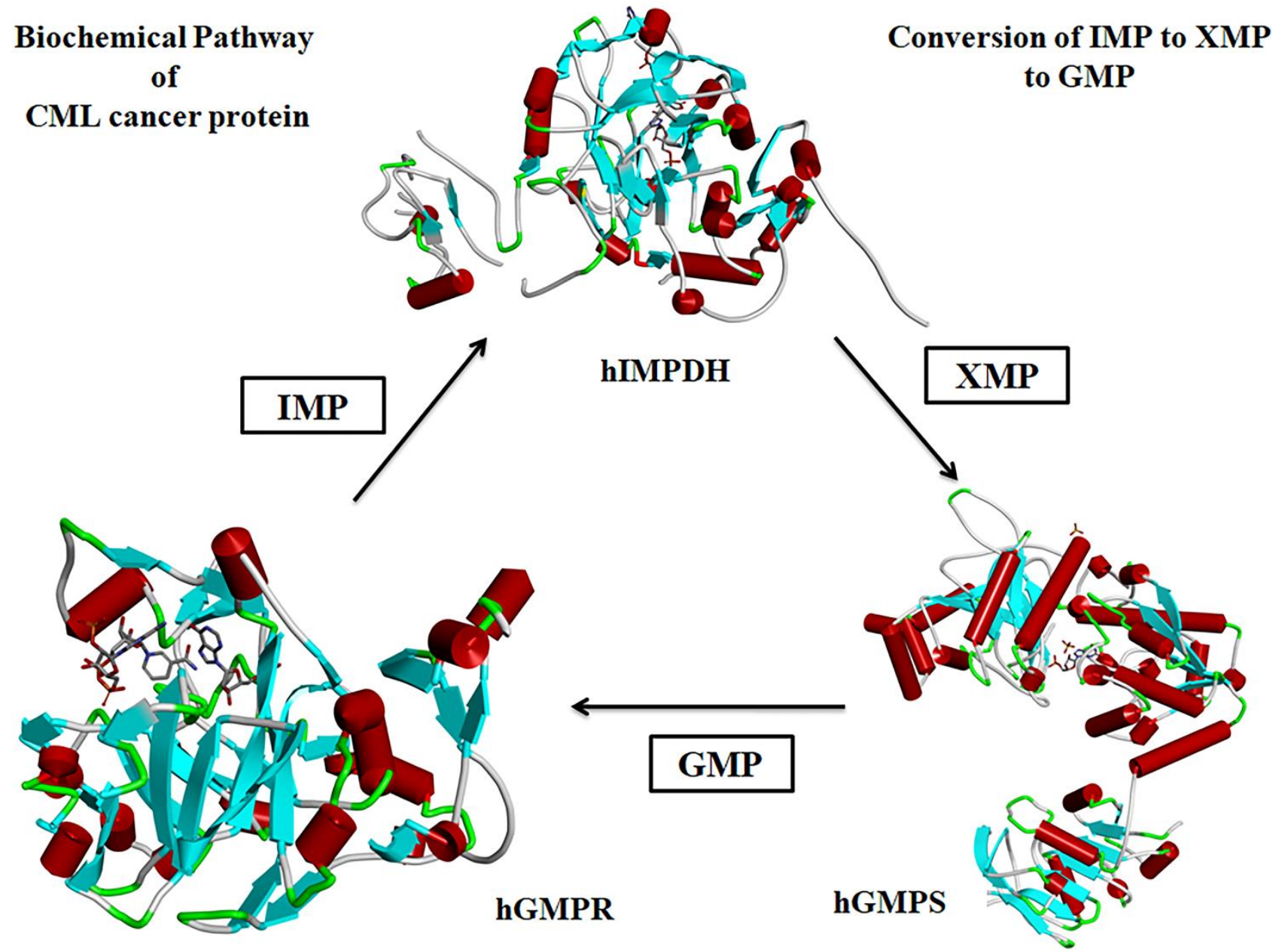

Figure S1: Biochemical pathway of purine nucleotide biosynthesis for interconversion of IMP (inosine monophosphate) to XMP (xanthine monophosphate) to GMP (guanosine monophosphate). The upper-middle figure shows the structure of hIMPDH (inosine monophosphate dehydrogenase) (PDB ID: 1NF7), the right lower panel shows the structure of hGMPS (guanosine monophosphate synthetase) (PDB ID: 2VXO) and the left lower panel shows the structure of hGMPR (guanosine monophosphate reductase) (PDB ID: 2C6Q). 


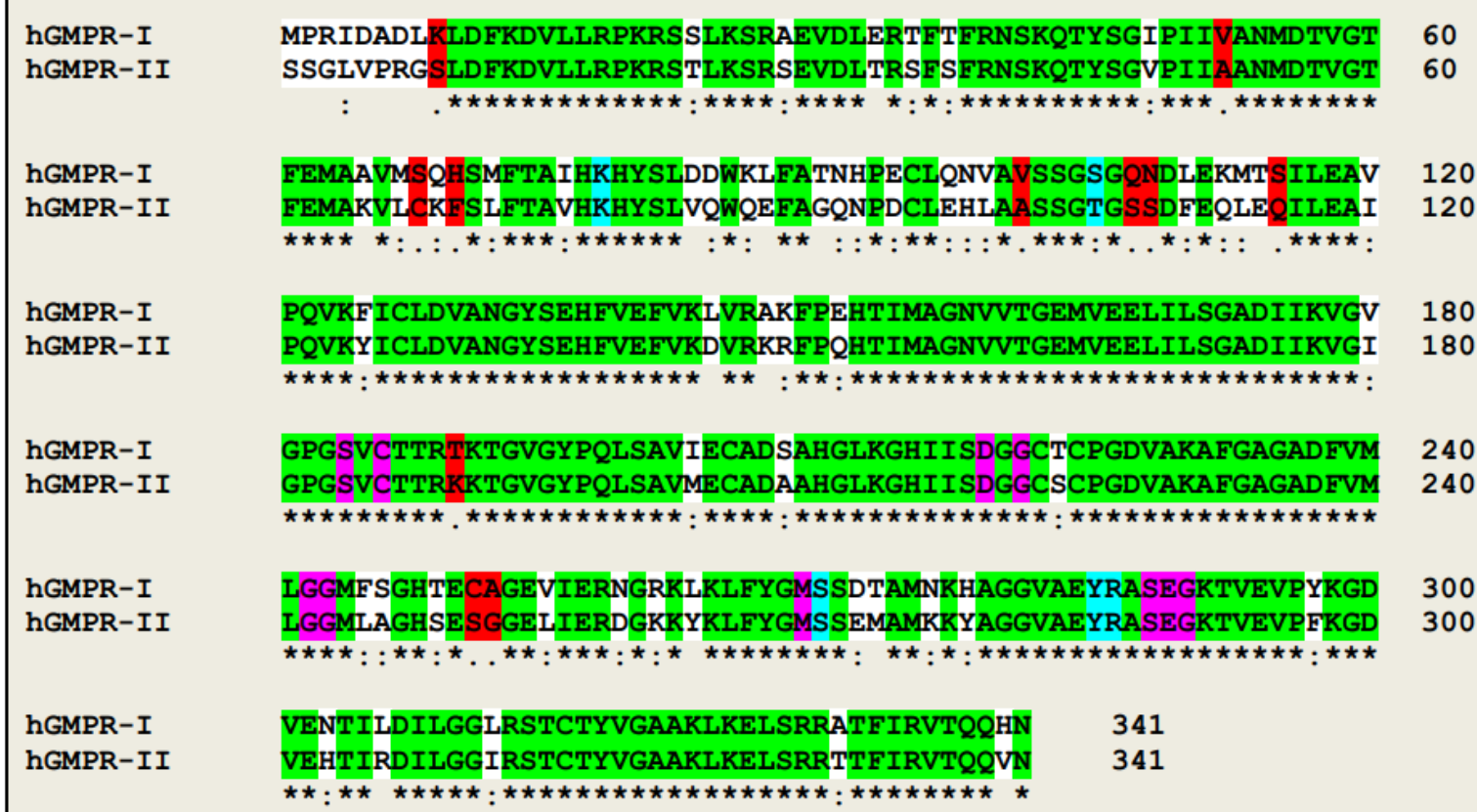

Figure S2: Sequence alignment between the two isoforms of hGMPR-I and II. The key residues of substrate (S184, C186, D219, G221, G242, G243, M269, S270, R286, S288, G290)/ product (S184, C186, D219, G221, G242, G243, M269, S270, E289) and the cofactor-binding pocket (K78, T105, S270, Y285, R286) are marked in pink and blue, respectively. The identical/similar, strongly dissimilar, and non-matching residues are shown in green, white, and red.

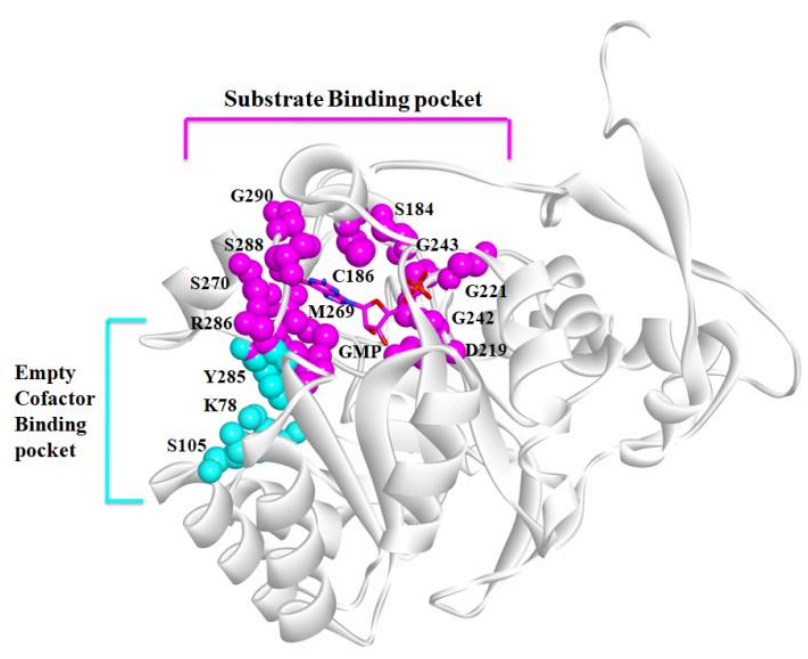

$\mathbf{A}$

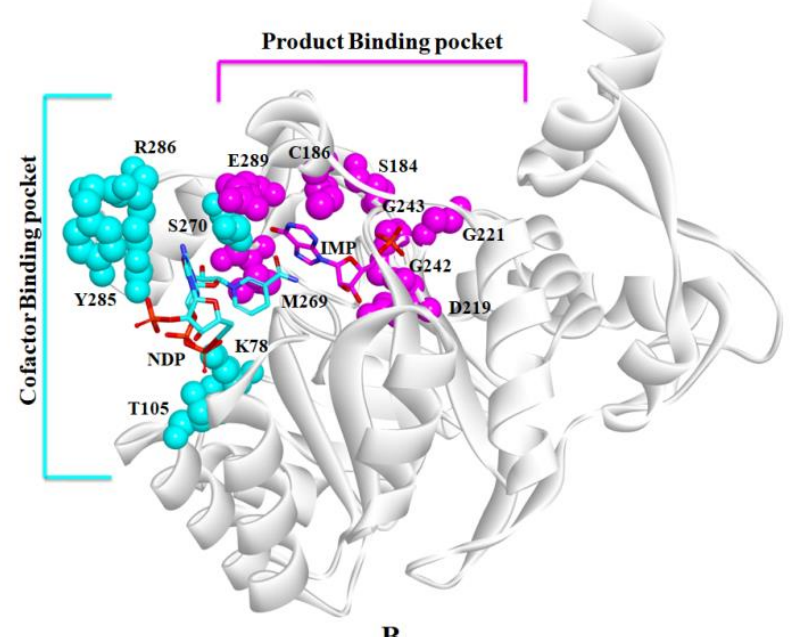

B

Figure S3: Residues of the two nucleotide-binding pockets in hGMPR I and II are shown as spheres, VDW and protein backbones are shown as white ribbons. (A) The substrate-binding site (pink) is occupied by GMP whereas NDP-binding pocket (blue) is empty in the hGMPR-I structure (PDB ID: 2BLE). (B) The product- (pink) and cofactor- (blue) binding sites have been accommodated by IMP and NDP in the hGMPR-II structure (PDB ID: 2C6Q). 


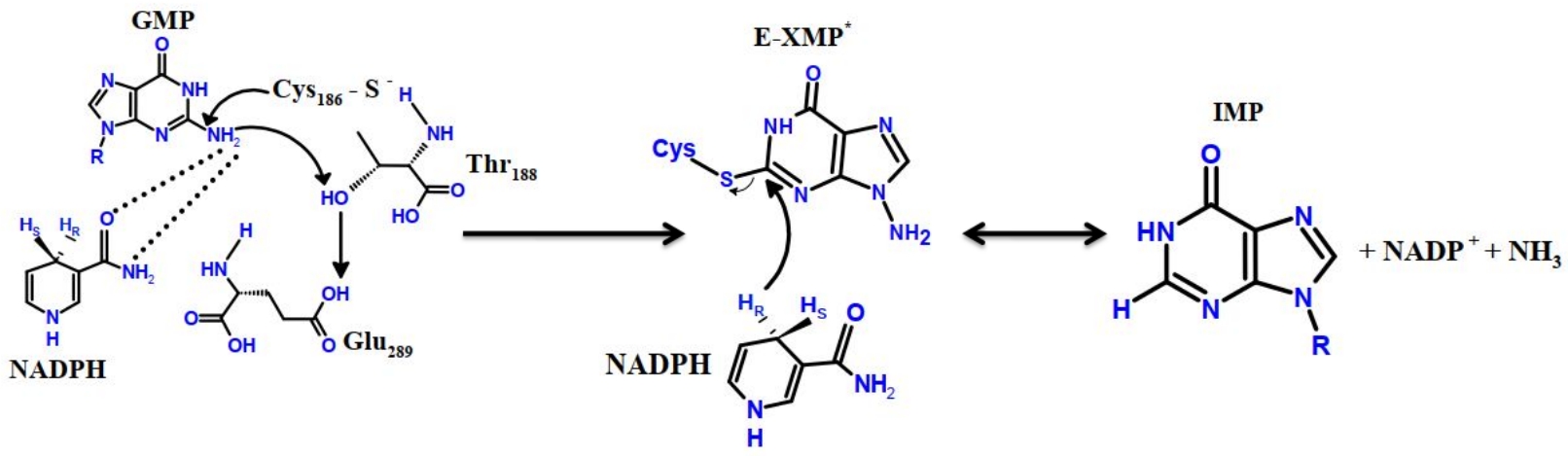

Figure S4: Catalytic mechanism from substrate GMP to product IMP via intermediate E-XMP in hGMPR enzyme.

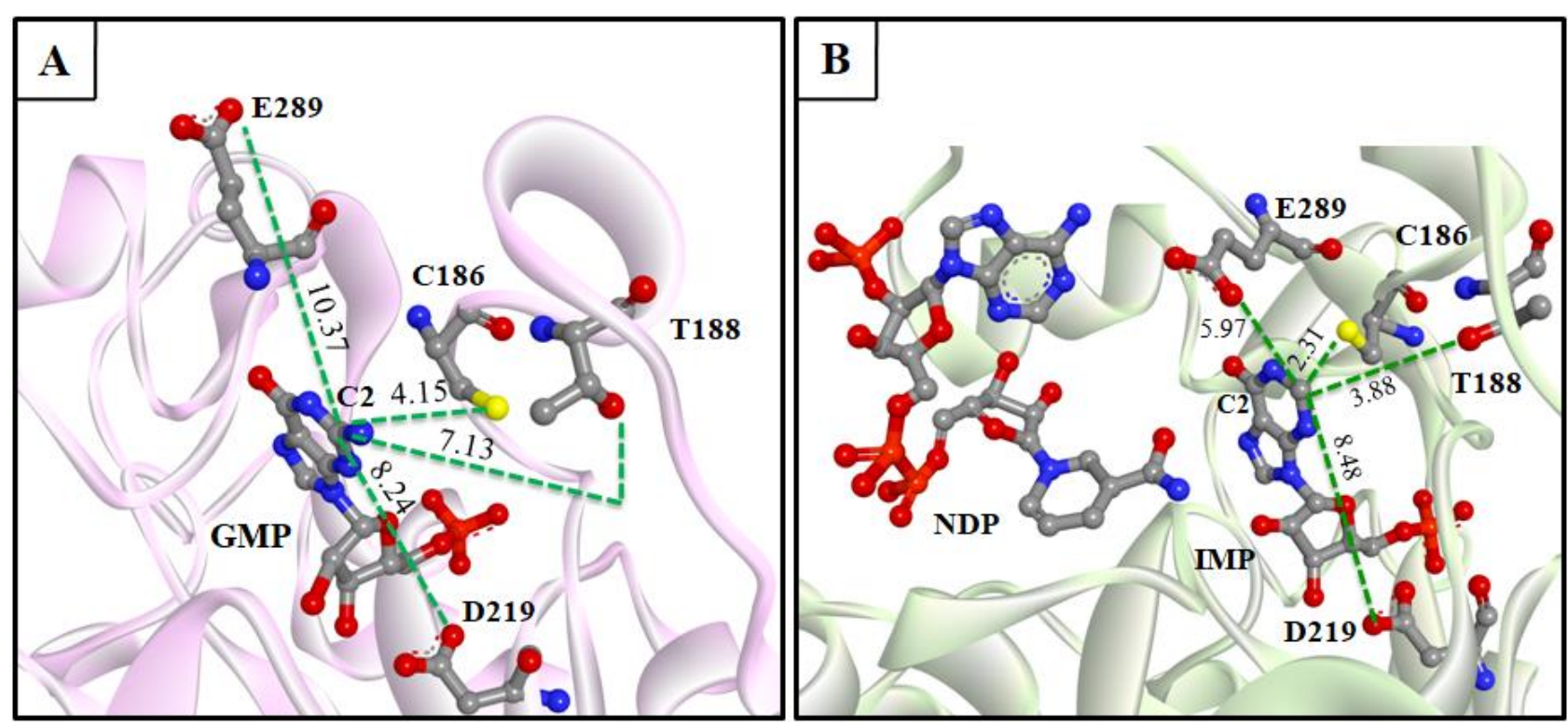

Figure S5: Interaction is shown between GMP or IMP (C2 atom) to the catalytic residue (Cys186) and noncatalytic residues (Thr188, Asp219, and Glu289) in the crystal structure 2BLE (left panel) and 2C6Q (right panel). The numbers indicate the distance (in $\AA$ ) between the C2 atom of GMP or IMP to residues (corresponding Table S2). 

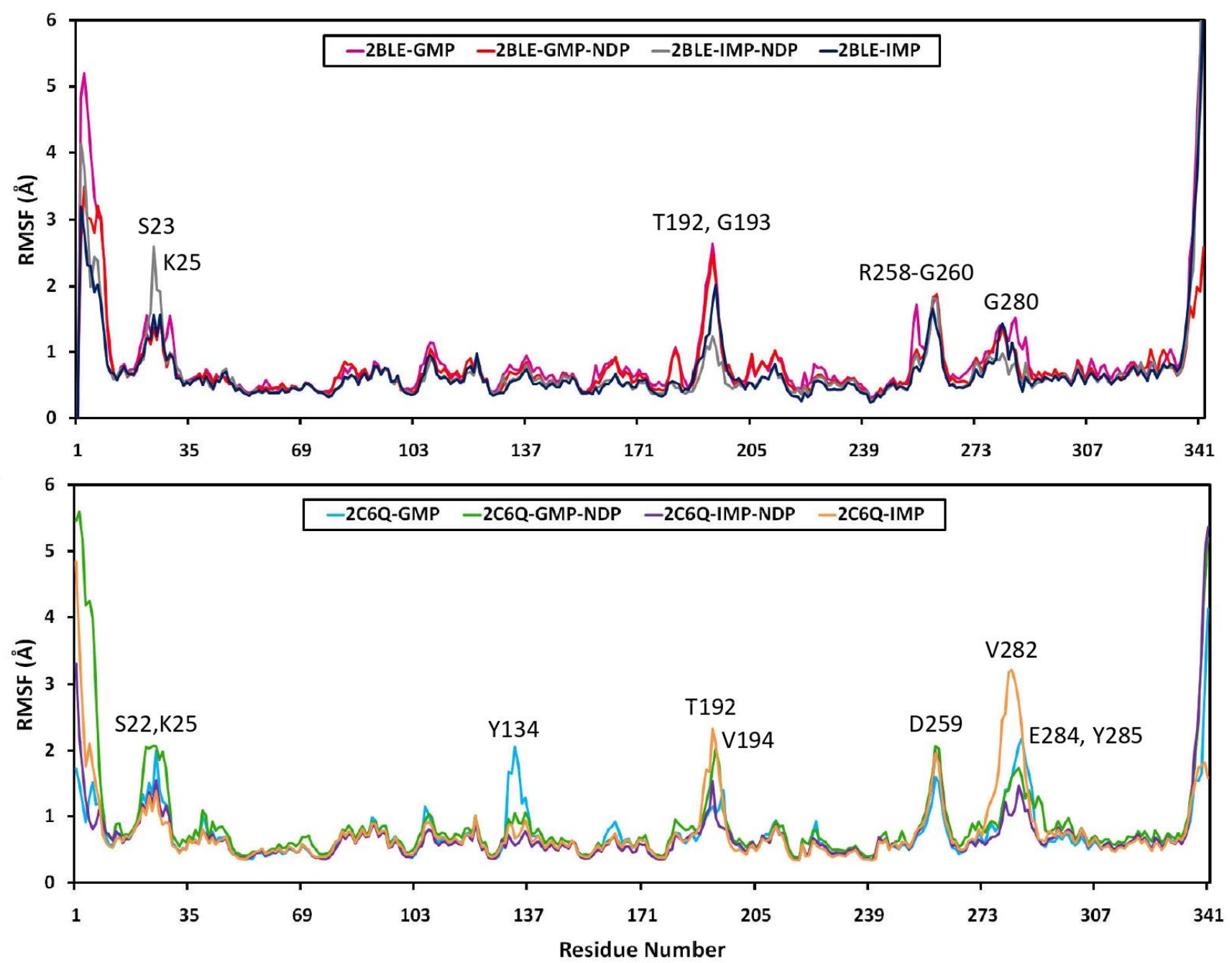

Figure S6: Top: comparison of CA RMSF values $(\AA)$ of each residue for conformations of GMP (pink), GMP-NDP (red), IMP-NDP (gray), and IMP (blue) in bound MD structures of 2BLE. Bottom: RMSF of GMP (light blue), GMP-NDP (green), IMP-NDP (purple), and IMP (orange) in bound MD structures for 2C6Q. The final 25000 frames for each conformation were used to calculate the RMSF. 

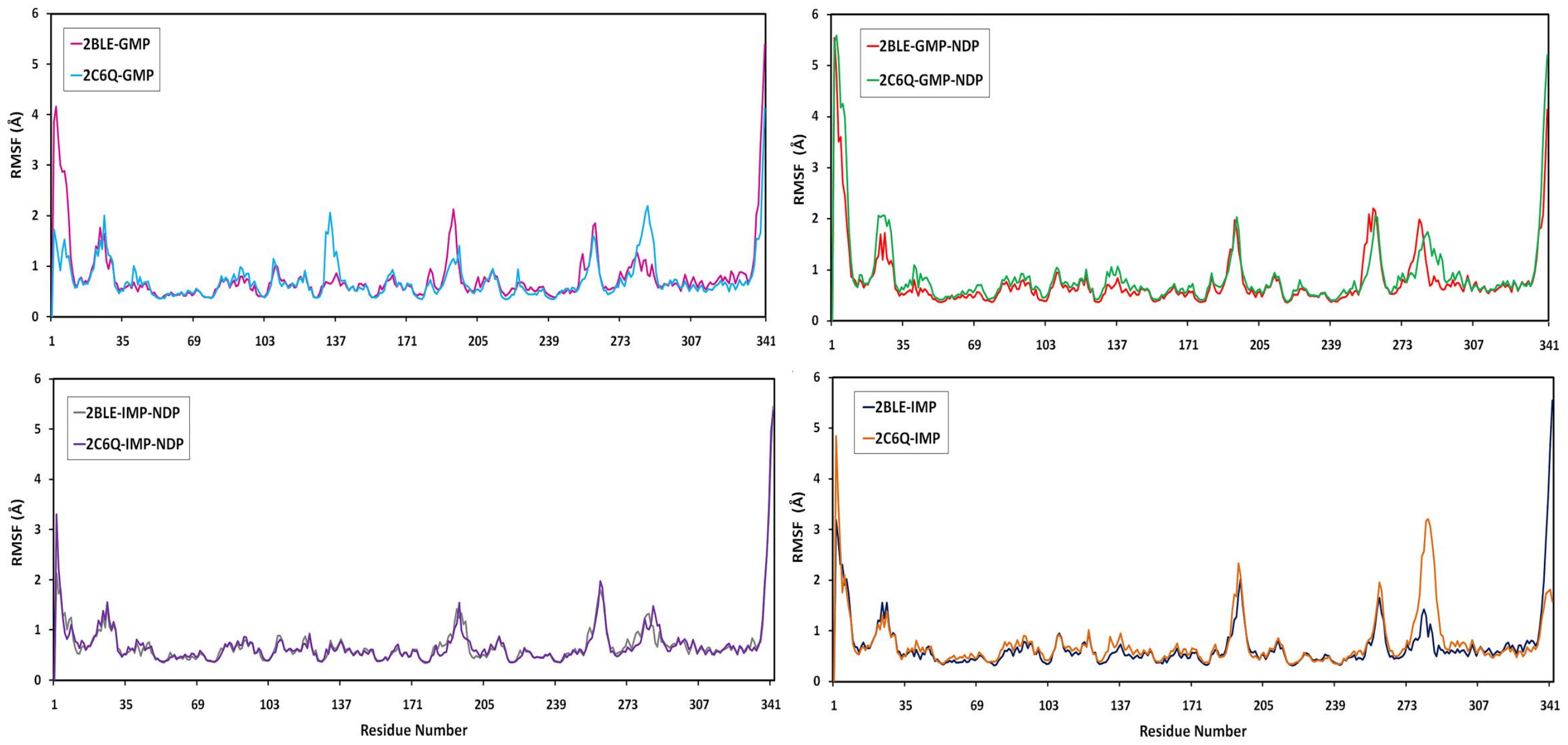
Figure S7: Comparison of RMSF ( $⿱$ ) of CA atoms between MD structures of 2BLE and 2C6Q. The upper left graph compares the RMSF value (CA atoms) between 2BLE with GMP (pink) and 2C6Q with GMP (light blue) bound MD structures. The upper right graph compares the RMSF values (CA atoms) between 2BLE-GMP-NDP (red) and 2C6Q-GMP-NDP (green) bound MD structures. The lower left graph compares the RMSF values (CA atoms) between 2BLE-IMP-NDP (gray) and 2C6Q-IMP-NDP (violet) bound MD structures. The lower right graph compares the RMSF values (CA atoms) between 2BLE-IMP (blue) and 2C6Q-IMP (orange) bound MD structures. The final 25000 frames obtained from each conformation were used. 


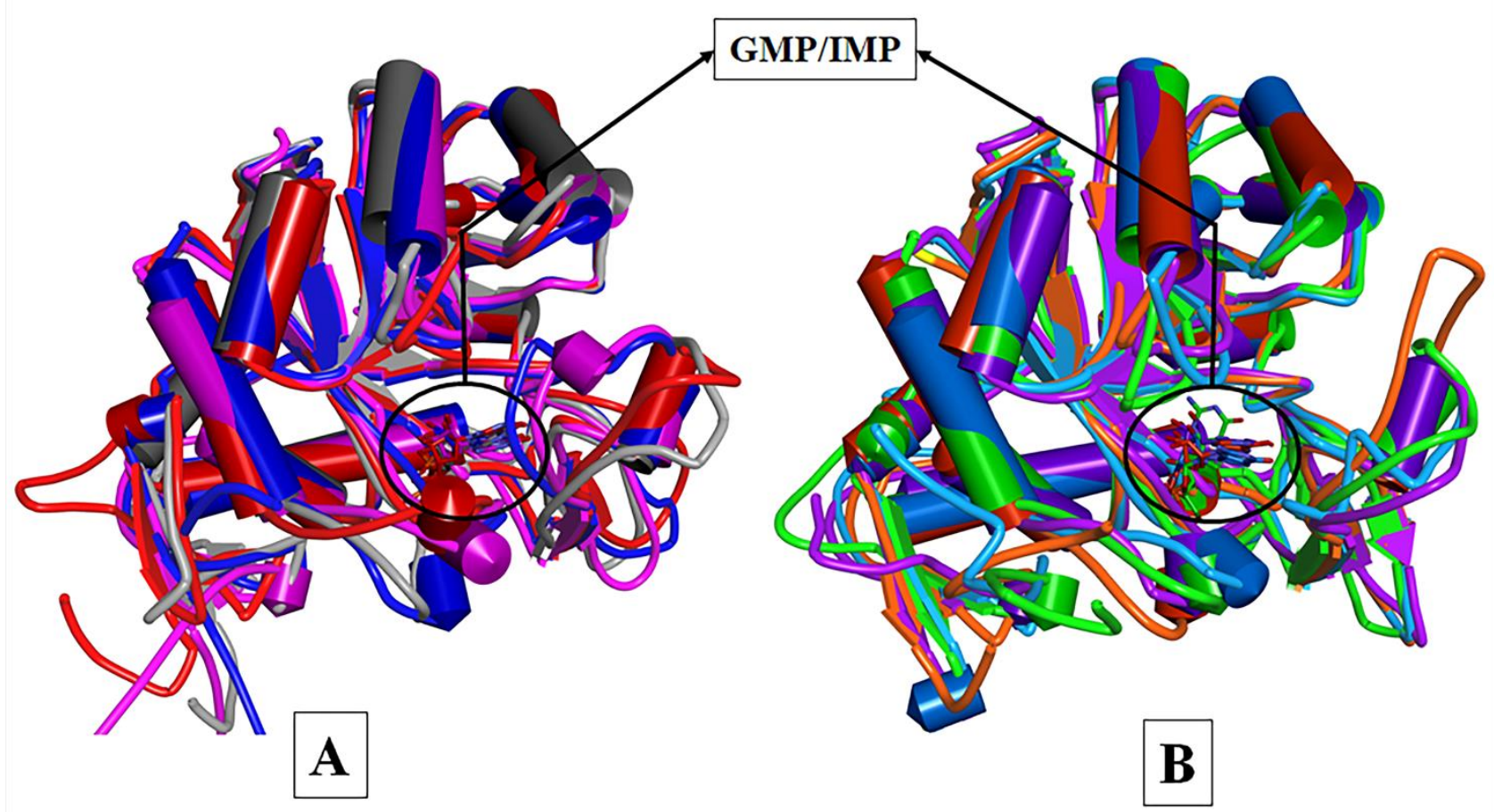

Figure S8: (A) Superimposed complexes for GMP, GMP-NDP, IMP-NDP, and IMP bound MD structures (average) in the MD structure of 2BLE. (B) Superimposed complexes for GMP, GMPNDP, IMP-NDP, and IMP bound MD structures (average) in MD structure of 2C6Q. 

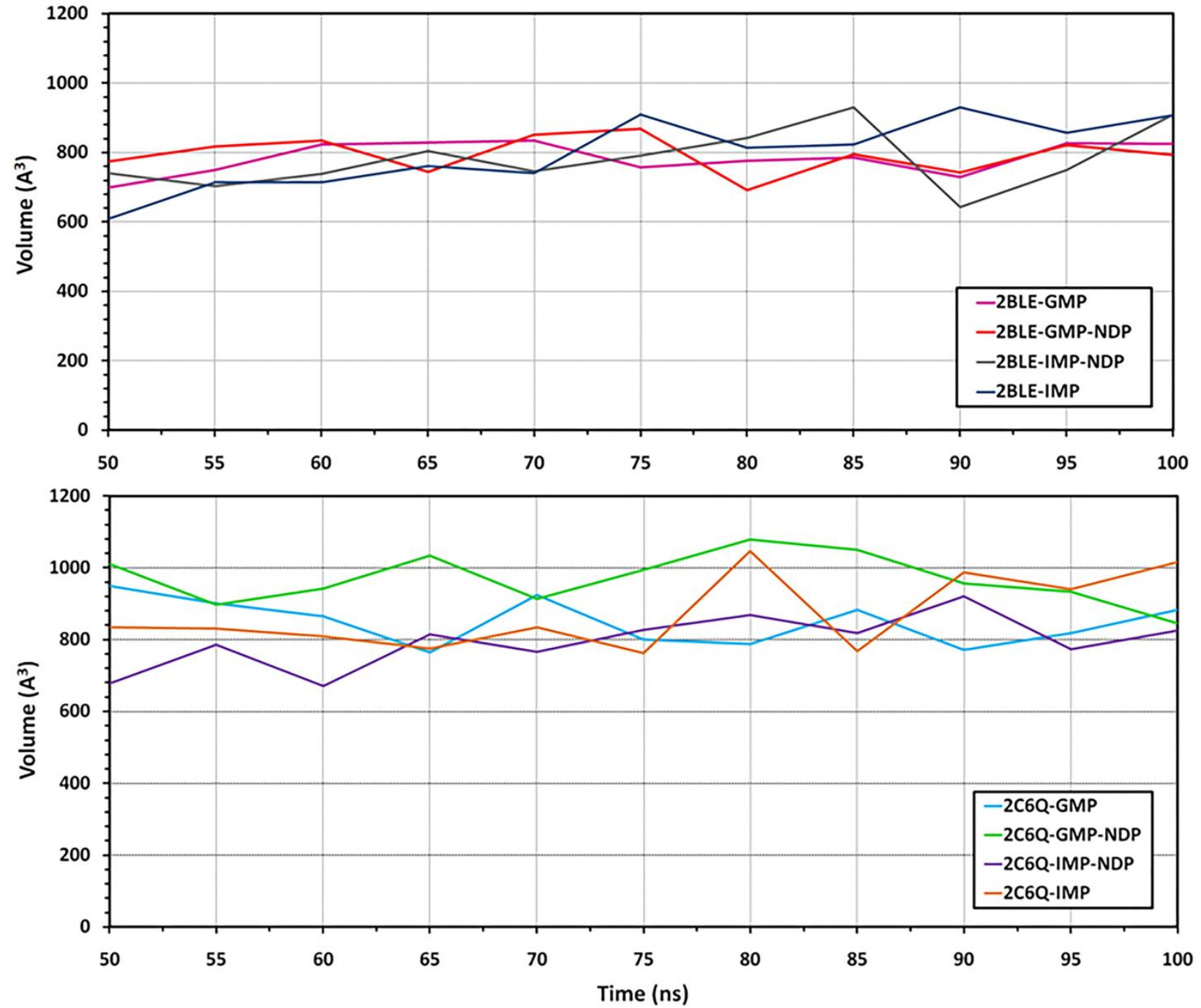

Figure S9: Top: Comparison of volumes $\left(\AA^{3}\right)$ for GMP (pink), GMP-NDP (red), IMP-NDP (gray), and IMP (blue) bound MD structures of 2BLE. Bottom: Volume of GMP (light blue), GMP-NDP (green), IMP-NDP (purple), and IMP (orange) bound MD structures in 2C6Q. The final 25000 frames for each conformation were used. 